\title{
La noble figura lírica de Gabriela Mistral.
}

Hay una nota de gravedad profunda que fija la posición de Gabriela Mistral frente a las otras grandes figuras femeninas de la poesía americana contemporánea. Una actitud propia un poco singular, de austero aislamiento en su mundo sombrío y desgarrádo, que revela cómo la poetisa pertenece a ese especie de almas que el dolor hace retirar a un recinto inexpougnable, Lqtesno abandonan nunca. El dolor llega a ella expreplenanejirventerd - en la etapa todavía dulce y tremante de la adolescencia-y deja una huella demasiado profunda para que sus relieves pudieran ser igualados por sabe Dios qué vientos de compensación o de alegría. Esta continuidad en una misma y aguda emoción la percibe con clarividencia Enrique Diez Canedo, al referirse a la obra de la poetisa: “. . . Podrían juntarse los dos libros - Desolación y Tala- en uno, sin que aumentara ni decayera esa impresión de hondura y altura que en pocos poetas, de hoy o de ayer, encontramos. Temas esenciales, sustancias, "materias", dan inspiración grande y serena a estos versos, en que no hallamos nada mezquino, o falto de elevación y solidez; y en cuyas formas rudas venimos en ocasiones a iden- 
tificarnos, arrebatados por las otras cualidades más fundamentales que nos hablan al corazón y a la mente...." (I)

Así destaca el crítico español la condición que preside el desenvolvimiento de esta obra trazada a golpe de buril, con la grave serenidad de los modelados clásicos. Desde las 1ríginas de "Desolación" libro carente de una verdadera uniclad temática, hasta estos recados que con sus voces estructurarán reciamente "Tala", la fisonomía es la misma, pero cada día con mayor nitidez y seguridad en los perfiles ya apuntados en su juventud.

También, su glosador, el crítico chileno Raúl Silva Castro (2) define su personalidad tan distinta de aquellas poetisas americanas, inclinadas a reflejar en sus versos deliquios amorosos de un legítimo o - muchas veces- simulado erotismo. El sentido de la nutjer es en Gabriela Mistral, no el de la enamorada, sino el de da fuadre. Por eso obedeciendo a una poderosa fuerza interior, su segundo libro se clenomina "Ternura". Con 1ãemoción de sus versos compensa la maternidad frustrada paradójicamente, en ella que tanto aspiró al hijo que 1 Bibliotece de Letritieras Lonpletar su designio sobre la tierra.Canta en todos los tonos a esta carne bendecida en la que debió perennizarse y cuya hora el destino detuvo. $\mathrm{Y}$ en este profundo desgarramiento interior es donde hay que buscar el germen de su arte y la razón absoluta de su poesía.

No es indispensable hablar de escuelas o de estilos literarios al tratar de Gabriela Mistral, ni ella ha demostrado predilección por una forma determinada. En las páginas de "Desolación" observamos su disposición para cultivar un soneto que maneja con absoluta despreocupación métrica; en

(1):-Tnrique Diez Canedo.-_Letras de América".-México, 1944.

(2).-Raúl Silva Castro.- “Ratudios sobre Gabriela Mistral"'. Santiago, 1935 
las páginas de "Ternura", los versos breves, facilitan con la levedad de su línea poética, el ritmo cantable de las rondas infantiles; por último en "Tala" demuestra poseer -entre otras cualidades - una rara aptitud para la moderna imagen que surge con frecuencia entre los octosílabos de un romance nervioso o en los diálogos de sabor cósmico de - por ejemplo- su poema "Cuenta - Mundo".

La crítica se ha inclinado con frecuencia a ubicar a la poetisa dentro del movimiento modernista. Razones cronológicas de su aparición en el ambiente americano y posiblemente apreciaciones de forma o contenido de alguno de sus versos pueden explicar esta opinión. Sin embargo el instinto agonista que predomina en sus poemas la vincula, más bién, a las nuevas expresiones de la lírica contemporánea y la lectura del último de sus libros nos trae la honda convicción, de que nos encontramos, frente a una de las más grandes figuras de la poesía de hoy, plena de sentido humano y rotunda en su emoción social.

\section{FL SENTIDO DE I.A "WIDARecinelli Lonverso"}

Decir la palabra vida tiene una elocuencia insospechable para explicar la razón de la obra de muchos escritores, In Gabriela Mistral existe, una estrecha interdependencia entre la primera etapa de su vida, y la obra de toda ella. Quien no recuerde, aunque sea en forma rápida, la anécdota de su adolescencia y su primera juventud, difícilmente podría dar en la clave de muchos aspectos de su obra poética, precisamente de aquellos que le han dado este tono universal de dolor, que surge de la entraña misma de su inspiración.

Lucila Godoy Alcayaga - tal el nombre auténtico de la poetisa- nació en la ciudad de Vicuña, en Chile, el 6 de 
Abril de r889. Es una tierra templada con valles apacibles y floridos y "sus moradores no conocen las privaciones, aunque muchos viven en la pobreza y no pocos soñando en el resurgimiento de la edad de oro o de plata o de algún tónico que venga a concentrar el vigor de los minerales de cobre, tan abundante como anémicos", al decir de Agustín Edwards. (3) Era su padre don Jerónimo Godoy, profesor de escuela que abandonó el hogar poco tiempo después de nacida su hija, y su madre doña Petronila Alcayaga en cuya familia existía también la vocación por la enseñanza que por tantas razones habría de despertar en la futura poetisa. Sus primeros años transcurrieron en la campiña, con la única variante de pasar de Vicuña a Monte Grande, donde vivió lo mejor de su niñez, desde los tres hasta los nueve años. El ambiente familiar era un clima propicio para determinar su destino y, siendo todavía muy joven, a los quince años, podemos observadrlas desempeñando el puesto de ayudante en una escuela rural de Coquimbo. Al mismo tiempo nace en su alma la imperativa necesidad de escribir, y en esta remota fecha deJigoufciencontramos las primeras manifestaciones de su pluma, teñidas de la agitada influencia romnántica.

Pero cinco años después, ocurre dentro de su existencia, el hecho que ha de trazar la dirección definitiva en su inspiración. Los veinte años de la poetisa responden al eterno llamado del corazón. Si soledad de maestra campesina, se llena de luz con la presencia del que ha de ser su compañero y hay una melodia de esperanza que se extiende sobre el porvenir. Cuando parecía que nada podría interrumpir el curso de sus amores, un desgraciado acontecimiento hace que, Romelio Ureta, su prometido, ponga fín a su vi-

(3).-Agustín Edwards.- "Mi tierra". 
da en forma inesperada y dramática. El dolor llega así para Gabriela, que en su seudónimo quiere tributar un homenaje de admiración al gran Mistral, y sólo acierta a componer versos tremantes, en los que descubrimos la decisión de toda su vida:

"Mi madre ya tendrá diez palmos

de ceniza sobre la sien.

No espigará entre mis rodillas

un niño rubio como mies.

Por hurgar en las sepulturas, no veré el cielo ni el trigal.

De removerlas la locura

en mi pecho se ha de acostar.

$Y$ como se van confundtendo

los rasgos del que he de buscar

cuando penetre en la Luz Ancha,

no lo podré enconterar diamés

Todavía por ésta época no tiene una verdadera formación literaria. En una antología compilada por Luis Carlos Soto en 1908, confiesa ingenuamente que su autor predilecto es Vargas Vila. Sin embargo el golpe decisivo de la muerte del ser amado, estimula su deseo de superarse, para cultivar más dignamente su memoria. Viaja a Santiago en I9Io y rinde exámenes en la Escuela Normal, abriendo así un campo más amplio a sus actividades. Se inicia para ella una nueva existencia. Reside en Antofagasta entre I9I I y I9I2 y luego es trasladada a Los Andes.

El año de“ 19I4, en Santiago, se realizan los Juegos Florales. Ella maestra desconocida y abnegada, concurre con 
sus "Sonetos de la Muerte". La revelación es definitiva, y su nombre se convierte en nacional. No obstante, la carrera del profesorado está tan profundamente enraizada en su alma, que continúa trabajando en distintas regiones de su patria: Punta Arenas, Temuco y luego Santiago. En esta labores transcurre ocho años, hasta que en I922 recibe la invitación que podría serle más grata entre todas. El Gobierno Mexicano, rindiendo tributo a su dedicación como maestra y a su alta inspiración de artista, le pide que colabore en los planes de organización educacional. La noble figura de Vasconcelos le da la bienvenida y en el gran país de los aztecas, trabaja infatigablemente y confronta nuevos paisajes y distintas bellezas. Allí compone sus "Lecturas de Mujeres" (I924), mientras que pocos meses antes había visto la luz, gracias al diligente interés del "Instituto de las Españas" de New York, la/primęa edición de su libro "Desolación".

Europa abre las maravillas de su cultura ante los ojos de la poetisa, el año débrigłsa HEalyetuns paréntesis por su ré-

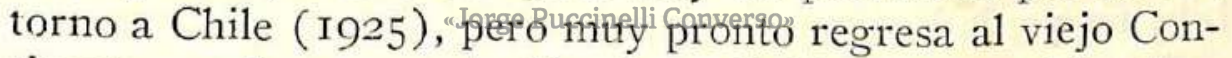
tinente con la representación de su Gobierno ante el Instituto de Cooperación Intelectual de la Liga de las Naciones. Reside una larga temporada en Francia e Italia y en I930 visita los Estados Unidos. Viajera impenitente llega a Cuba, Puerto Rico, Panamá, El Salvador y Guatemala, reintegrándose a Europa en I932, dentro de la carrera consular, primero en Génova y luego en Madrid y Río de Janeiro, en cuyas tibias playas una de estas tardes ha recibido la maravillosa noticia de haber sido agraciada con el premio Nobel, ristinción que muy contadas mujeres en el mundo han alcanzado a obtener. 


\section{LAS RAICES DE SU INSPIRACION.}

Mucho se ha escrito ya sobre Gabriela Mistral. Desde 1a loa encendida y adicta, hasta el juicio analítico y un poco implacable de quienes se han complacido en destacar defectos de versificación como grandes hallazgos de sus flaquezas huraanas. También se ha recordado con insistencia su orgullosa posición en el dolor, que Domingo Amunátegui del Solar destaca: "Gabriela Mistral —dice-se distingue por su espiritu rebelde. Llora a gritos sus desgracias, y se atreve a reclamar justicia ante el tribunal de Dios". Y añade "como el poeta Zorrilla, nació a la vida literaria al borde de la tumba de un suicida...." (4) Efectivamente el dolor es el eje de su creación poética, pero lejos de prorrumpir en voces destempladas, su angustia es un movimiento hacia adentro que desgarra sus entrañas en-silencio. Indudablemente que su tragedia la obliga à buscar un refugio, y este es la religión. De aquí nace el apresurado juicio de considerar que la poesía de Gabriela Mistral tiene una atmósfera mística. Exhibe en verdad, sinjplientente Lefras anto de una persona que sufre y que sufre intensamente. Vió, allá en los años de su juventud, en el amor la figura del hijo, y esta maternidad frustrada se manifiesta descle sus versos primigenios hasta culminar en las variadas formas de "Ternura" y reaparecer muchos años después, en las páginas de "Tala".

El hijo es para Gabriela Mistral una forma cósmica que emerge de su palabra para identificarse con un hálito universal que se confunde con la especie. Hasta cuando su voz se adelgaza para intentar un suave canto infantil, surge de pronto, entre la frágil melodía, un acento más hondo, inás denso, más atormentado, que revela el trasfondo de su (4).-Domingo Amunátegui del Solar.- "Letras Chilenas".-Santiago, $\overline{1934 .}$ 
alma de mujer levantándose contra el destino como en una protesta desgarrada. Hay algo de esa tremenda catarsis que nutría el argumento mismo de las tragedias clásicas y que ayudaba al pueblo a una depuración espiritual. La sonrisa se cierra siempre que leemos a Gabriela Mistral en el rictus doloroso o melancólico de algún suceso inexplicable que puede sobrevenir. Es como si la poetisa defendiera de los males del mundo, el niño que na pudo venir.

La serena fortaleza de un cristianismo profundo pone, sin embargo, una nota de placidez en su discurso. Después de las voces atormentadas de los sonetos "Al oído de Cris10", viene la dulce y soleada visión de "Ruth" o una de esas estampas del ingenuo primitivismo de las pinturas medioevales, cuando describe desvaídamente "El Angel Guardián".

Pero el leit-motiv de_esta sulpoesía es la ecuación $m a$ dre-hijo. En el poema dedicado a Alfonsina Storni, reclama la carne de sus entrañas, con una pasión que vence todas las censuras:

Biblioteca de Letras "Jorge Puccinelli Converso"

¡Un hijo, un hijo, un hijo. Yo quise un hijo tuyo y mío, allá en los días del éxtasis ardiente en los que hasta mis huesos temblaron de tu arrullo y un ancho resplandor creció sobre mi frente..."

No obstante el destino le responde con aspereza, y to que pudo ser un jardín, es gris desierto; y de donde debió haber sonrisas, solo hay amargura y silencio. Unicamente le queda el derecho a quejarse, y prorrumpe.

"No sembré por mi troje, no enseñé para hacerme un brazo con amor para la hora postrera, 


\section{$-334-$}

, cuando mi cuello roto no pueda sostenerme y mi mano tantee la sábana ligera.

"Apacenté los hijos ajenos, colmé el troje con los trigos divinos, y solo de ti espero ¡Padre nuestro que estás en los cielos! Recoge mi cabeza mendiga, si en esta noche muero!...."

La figura de Cristo se destaca en su libro en un clarooscuro que acentúa vigorosamente sus rasgos, y baña el alma de la poetisa en una reconfortante salud espiritual. Así es como puede elevarse sobre su dolor, para entregarse a la suprema tarea de educar a los niños derramando sobre ellos esa luz, que para ella se cortó brusca y definitivamente. En "Ternura" descubrimos una Suite agradable y dulce, que con pequeños descansos nos muestra la variedad de sus melodías que parten del centro degravedad tonal enunciado en' su propio título. Es "Ternura" un breviario para las madres del mundo, que abre el eticanto de sus páginas con una clara nota de cariño, que no se olvida más:

"Dorge Puccinelli Converso"
"Duerme hijito, como semilla

en el momento de sembrar, en los días de encañadura

o en los meses de ceguedad...."

El sacrificio absoluto, la generosidad triunfante de la madre, aparece en otras estrofas como en las de aquel poema titulado "La madre triste" en que dice:

"Duerme, duerme, niño mío, sin zozobra, sin temor, aunque no se duerma mi alma, aunque no descanse yo....." 
O cuando enuncia como un credo o un desafío el antiquísimo grito de la especie, que ve en el hijo la continuidad de la raza, frente a todo y a todos:
"Meciendo mi carne
meciendo a mi hijo,
voy moliendo el mundo
con mis pulsos vivos...."

Y la forma del niño pone el don de su bullicio aún en las más ásperas breñas, y en las soledades sin eco. Lo enuncia con sobria elocuencia, en las tres breves estrofas de su poema "Yo no tengo soledad":

"Es la noche desamparo

de las sierras hasta el mar.

Pero yo la-cue te miece,

iyo no tengo soledad!

Es el cielogdesanteparoras

si la luriagedueciallifiarerson

Pero yo la que te estrecha

iyo no tengo soledad!

Es el mundo desamparo

- y la carne triste va.

Pero yo, la que te oprime, ¡yo no tengo soledad!....."

Entre la edición hecha por el Instituto de las Españas de la obra "Desolación" (1922) y "Ternura", aparecida en Madrid (1924), solo median dos años. En cambio qué larga distancia existe entre esta primera parte de su lírica y la impresión de "Tala" en las prensas de la revista "Sur" de 
Buenos Aires, el año de 1938 . Son quince años de meditación y de estudiar paso a paso su propio dolor y el dolor del mundo. En ese período la poetisa ha viajado mucho y ha purificado su sensibilidad con tantas experiencias. Igual en su recogimiento y clausura, sale únicamente de ella, ante el cordial llamado de Victoria Ocampo que le pide la publicación de un libro, cuyo producto se dedique a los niños españoles dispersos por el mundo por causa de una guerra en la que no tuvieron culpa: "Tomen ellos el pobre libro - dice- de mano de su Gabriela, que es una mestiza de vasco y se lave "Tala" de su miseria esencial por este ademán de servir, de ser únicamente el criado de mi amor hacia la sangre inocente de España, que va y viene por la Península y por Europa entera". Igual que Vallejo o Neruda, siente en la almendra de su intimidad la tragedia ibérica y lo expresa sin reticencias: Así es como nuace "Tala".

Hay un tema central que abre el nuevo volumen de versos. Este tema es-la madre de la poetisa. Su muerte arranca una de las notas más hondas de su lírica. Se figura caminar al lado defibleteca de Letras
"Madre mía, en el sueño
ando por paisajes cardenosos:
un monte negro que se contornea
siempre, para alcanzar el otro monte;
y en 'el que sigue estás tú vagamente,
pero siempre hay otro monte redondo
que circundar, para pagar el paso
al monte de tu gozo y de mi gozo....." (5)

Ante lo definitivo de su desaparición, reconstruye la

(5).-Gabriela Mistral.-“Tala”.-Ediciones Sur, Buenos Aires, 1938. 
imagen viva de la madre en una dulce anatomía de amor $y$. ie sufrimiento:

"Amados pechos que me nutrieron

con una leche más que otra viva;

parados ojos que me miraron

con tal mirada que me ceñía;

regazo ancho que calentó

con una hornada que no se enfría;

mano pequeña que me tocaba

con un contacto que me fundía...."

Si avanzamos en estremecido viaje por las páginas de este libro fundamental, apreciaremos el renacer del impulso que le hace buscar refugio, èn 'ambientes sobrenaturales:

"iCristo hijo de mujer

carne que aquí amanantaron,

que se actierdaideo una dnoches

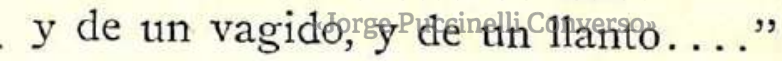

Su artesanía poética, ya muy enriquecida, demuestra un contorno español - muy Siglo de Oro- en octosílabos, como el que vais a oir, que exhiben sus figuras como imaginería barroca:
" $\mathrm{J}$ Jesucristo, carne amante
fuego de ecos, oído alto,
caracol vivo del cielo,
de sus aires torneado:
abájate a ella, siente
otra vez que te tocaron;
vuélvete a su voz que sube 
por los aires extremados, y si su voz no la lleva, toma la niebla de su hálito....."

De esta misma estirpe son composiciones como "La memoria divina", "Dos Angeles" o el "Nocturno del descendimiento".

Muy distinta, pero de idéntico interés, es aquella otra zona del libro que la poetisa denomina "América". El cuerpo del joven continente muestra sus vigorosos relieves a través de estos poemas. Pero - siempre- como si algo de atracción inexorable perviviera en su destino, las imágenes que emplea han de coincidir con el recuerdo de la dual preocupación de la madre y el hijo. En su poema "Cordillera", nos lo confirma:

"Cordillera de ios Andes, madre yacente y madre que anda, que de niños pos enloquece y hace morir cuando nos falta...."

Como José Santos Chocano en su época, se complace en describir la flora americana y en recoger leyendas o mitos muy antiguos. "El maíz" toma una personalidad desconocida y millonaria en sus versos; el "Mar Caribe" descubre el secreto de su existencia; Panamá y México, dejan una melodía perdurable.

Hoy día en que el mundo americano tributa su homenaje a este gran espíritu, quiere recordar a Gabriela Mistral a su paso por el Perú, identificándose con nuestra tierra, y que nos acompañó en una tarde inolvidable en que nosotros quisimos mostrarle cómo era nuestra música y danza 


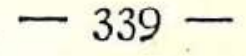

populares, a plena luz y en medio del campo, tendiendo su amistad ancha y segura como una gran camarada en el arte $y$ en la vida.

\section{Luis Fabio Xammar.}

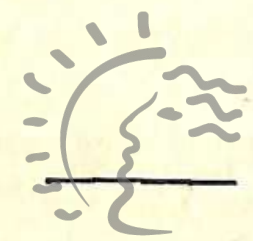

Biblioteca de Letras

"Jorge Puccinelli Converso" 